\title{
AS FRONTEIRAS INTERNAS DA NAÇÃO: PENSANDO O COLONIALISMO A PARTIR DA LITERATURA ANGOLANA
}

\author{
Anselmo Peres Alós
}

\begin{abstract}
RESUMO: a intenção desta reflexão é a de pensar a obra do romancista angolano Artur Carlos Maurício Pestana dos Santos (cujo pseudônimo literário é Pepetela) a partir de um olhar crítico comprometido com a questão do surgimento dos novos nacionalismos africanos, depois da transformação das velhas colônias portuguesas da África em Estados Nacionais independentes. Comprometendo-se com a perspectiva dos estudos pós-coloniais, particularmente os de Edward Said e Homi K. Bhabha, explora-se criticamente os limites das fronteiras internas da nação no texto literário.
\end{abstract}

PALAVRAS-CHAVE: Literatura Angolana - Crítica Pós-colonial - Nacionalismo e Literatura

RESUMEN: la intención de esa reflexión es la de pensar la obra del novelista angolano Artur Carlos Maurício Pestana dos Santos (cuyo pseudónimo literário es Pepetela) a partir de una mirada crítica comprometida con la cuestión del surgimiento de los nuevos nacionalismos africanos desde la transformación de las viejas colónias portuguesas en África en Estados Nacionales independientes. Comprometiéndose con la perspectiva de los estudios poscoloniales, en especial los de Edward Said y Homi K. Bhabha, la idea que se presenta acá es la compreensión crítica de los límites de las fronteras interiores a la nación en el texto literário.

PALABRAS-CLAVE: Literatura Angolana - Crítica Poscolonial - Nacionalismo en Literatura

\section{INTRODUÇÃO}

Nem o imperialismo, nem o colonialismo é um simples ato de acumulação e aquisição. Ambos são sustentados e talvez impelidos por potentes formações ideológicas que incluem a noção de que certos territórios e povos precisam e imploram pela dominação, bem como formas de conhecimento filiadas à dominação: o vocabulário da cultura imperial oitocentista clássica está repleto de palavras e conceitos como "raças servis" ou "inferiores", "povos subordinados", "dependência", "expansão" e "autoridade". E as idéias sobre a cultura eram explicitadas, reforçadas, criticadas ou rejeitadas a partir das experiências imperiais. (SAID, 1995, p. 40)

- [...] Acho que são todos iguais e qualquer que seja o Movimento que fique no Governo vai-me lixar. Sem ter em consideração os anos que trabalhei para esta terra, a abrir estradas, a organizar recenseamentos, a cobrar impostos etc. Tudo isso era para o bem do País, ou não?

- Para bem do colonialismo - disse Olívia. - Tens de distinguir as coisas.

\footnotetext{
* Doutor em Estudos de Literatura - Literatura Comparada - pelo Programa de Pós-Graduação em Letras da Universidade Federal do Rio Grande do Sul. E-mail: anselmoperesalos@yahoo.com.br. Gostaria de agradecer à Profa. Dra. Jane Tutikian pelas críticas e sugestões a uma primeira versão deste artigo.
} 
- Colonialismo, colonialismo, não têm outra palavra na boca. Mas o tal colonialismo é que desenvolveu essa terra.

- Desenvolveu nada, bolas - disse Olívia. - Só foi para benefício da burguesia exploradora.

- O teu pai é um burguês então?

- Claro. E dos grandes. Qual é a dúvida? Primeiro não se chateava nada que o dissessem, até ficava orgulhoso. E o sonho de todos vocês era serem grandes capitalistas como ele. Então por que agora não assumem? (PEPETELA, 1984, p. 252)

O presente artigo pretende, a partir do romance Yaka, de Artur Carlos Maurício Pestana dos Santos (que adotou como pseudônimo o nome Pepetela), refletir sobre a constituição da identidade nacional angolana. Tomando-se como referencial teórico a obra de Edward W. Said e Homi K. Bhabha, o que se pretende em um primeiro momento é avaliar como a nação é construída discursivamente enquanto identidade monolítica, partindo do conceito de uma cultura nacional. Em seguida, pretende-se identificar as contradições que estão circundadas por essa idéia essencialista de nação, rastreando as fronteiras internas à mesma. Para isso, se entrecruza o discurso ficcional com o histórico, sendo o último pensado também como uma articulação de linguagem construída a posteriori do acontecimento histórico propriamente dito (ou, em outras palavras, uma interpretação do acontecimento histórico). Dessa forma, se constitui a própria história, em certa medida, também como um discurso ficcional.

Edward Said, em Cultura e Imperialismo (1995), desenvolve uma crítica à leitura imperialista do cânone literário, leitura essa que parte do divórcio entre as esferas política e cultural dentro de uma comunidade nacional. Nessa obra, a questão da representação reveste-se de central importância, particularmente no momento em que Said desenvolve sua crítica à desarticulação entre representação cultural e contexto político. Diz ele que o exercício das diferentes formas de poder cultural, voltado para o interior da própria esfera cultural, estabelece um espaço hierarquizado no qual são incluídos os objetos que vão se caracterizando como verdadeiramente nacionais ao mesmo tempo em que são excluídos os que não são considerados como tal. Tal espaço, que se pode definir como o campo discursivo canônico - visto enquanto conjunto de bens culturais e/ou simbólicos representativos da nacionalidade - se apresenta como se fosse livre e dissociado da esfera política, que é vista como degradada, "onde se supõe ocorrer a verdadeira luta entre interesses" (SAID, 1995, p. 93). Nessa separação entre a esfera política e a esfera cultural, Said afirma que há um apagamento radical de interconexões irredutíveis, pois a cultura é "exonerada de qualquer envolvimento com o poder, as representações são consideradas apenas como imagens apolíticas a ser analisadas e interpretadas" (ibid., p. 93). Em verdade, a instância do político sempre "contamina" (no sentido derrideano do termo) a economia do campo literário, dado o próprio estabelecimento de um cânone nacional ganhar legitimidade, em parte, pelo escamoteamento ou des-reconhecimento das relações subjacentes de poder que possibilitaram a sua constituição e possibilitam a sua reprodução.

De acordo com Bhabha, em O Local da Cultura:

A pós-colonialidade [...] é um salutar lembrete das relações "neocoloniais" remanescentes no interior da "nova" ordem mundial e da divisão do trabalho multinacional. Tal perspectiva permite a autentificação de histórias de exploração e o desenvolvimento de estratégias de resistência. Além disso, no entanto, a crítica pós-colonial dá testemunho desses países e comunidades no norte e no sul, urbanos e rurais - constituídos, se me permitem forjar a 
expressão, "de outro modo que não a modernidade". Tais culturas de contramodernidade pós-colonial podem ser contingentes à modernidade, descontínuas ou em desacordo com ela, resistentes a suas opressivas tecnologias assimilacionistas; porém, elas também põem em campo o hibridismo cultural de suas condições fronteiriças para "traduzir", e portanto reinscrever, o imaginário social da metrópole como da modernidade (BHABHA, 1998, p. 26)

Assim, se torna difícil encarar a obra de Pepetela como expoente de uma estética pós-moderna, ainda em seus escritos se possa encontrar aquilo que de mais pósmoderno há na produção literária, de acordo com o que Linda Hutcheon expõe em $A$ Poetics of Postmodernity (1988). Embora a maioria dos romances de Pepetela traga as duas principais características daquilo que Hutcheon chama de metaficção historiográfica (a saber: a ficcionalização e reescritura do discurso histórico oficial, acompanhadas de uma reflexão sobre o ato da escritura do mesmo, e da própria reescritura promovida pelo exercício literário pós-moderno), é quase que um oxímoro tratar como pós-moderna uma narrativa que (tanto no nível diegético quanto no contexto histórico de produção/escritura) trata de um universo no qual o colonialismo português (e não a modernidade, com seus pressupostos liberais e racionalistas) se constituiu como condição histórico-social de produção das representações culturais, mais especificamente as de cunho literário. É o tipo de situação que se pode presenciar não apenas na obra de Pepetela, mas no que toca a praticamente toda a literatura angolana.

Toda a obra de Pepetela - em especial os romances Mayombe (1980) e Yaka (1984) - mostram que a experiência pós-colonial tem um peso muito grande na produção literária, ao contrário do que acontece na literatura produzida no império. Se é verdade que na Europa há a dissociação entre política e cultura identificada por Said, em Angola (e particularmente nos escritos de Pepetela) o que se vê é exatamente o contrário: uma aguçada percepção das inter-relações existentes entre as representações culturais e a realidade política da nação angolana. É a partir da (re)criação de mitos nacionais, ficcionalizando em forma romanesca as histórias da rainha Lueji, ou criando um novo deus híbrido, um Prometeu-Ogun, a partir do protagonista central do romance Mayombe, que Pepetela busca fazer sua colaboração para reerguer culturalmente um país que, embora tenha conquistado sua independência política em 1975, continua até hoje enfrentando sérios problemas, como a guerra civil, resultante do tribalismo que remonta ao período colonialista, como Pepetela tão bem nos mostrou em Mayombe.

Em Mayombe, Pepetela aponta sua preocupação com as fronteiras internas da nação angolana - a partir do momento em que inclui na diegese narrativa a questão do tribalismo -, problematizando a construção de mais uma ficção discursiva (a de uma identidade nacional coesa e, tal como a define Said, monolítica). Contudo, é no romance Yaka que tal preocupação será levada ao máximo grau. Enquanto em Mayombe Pepetela preocupa-se com a fragmentação gerada pelo tribalismo, em Yaka o escritor vai mostrar como os interesses dos próprios colonos brancos em território angolano não estão cristalizados apenas sob a égide da raça ou da condição de colono, mas sim sob uma complexa rede de filiações que incluem, entre outras matrizes identitárias, as de raça, obviamente, mas também as de gênero e de classe social. 


\title{
ÓSCAR E ALEXANDRE: O DEGREDO E O COMEÇO DA DINASTIA SEMEDO
}

O romance Yaka traz a trajetória da dinastia Semedo, desde a chegada do grande patriarca Óscar Semedo, degredado por ser republicano (ou por ter assassinado a primeira mulher a golpes de machadinha, não se sabe ao certo) até o envolvimento de Joel Ulisses, neto de Alexandre, com o Movimento pela Libertação Total de Angola (MPLA). Cinco gerações de brancos que construíram suas vidas - uns a contragosto, outros nem tanto - sobre território negro.

O fio condutor da narrativa é o olhar de Alexandre Semedo. O pai de Alexandre, Óscar Semedo, é degredado para Angola e condenado a dez anos de trabalhos agrícolas. Óscar casa com Esmeralda, uma branca de segunda ${ }^{1}$ ou, mais exatamente, "a primeira branca a nascer em Campagombe" (PEPETELA, 1984, p. 10). Alexandre, filho de um degredado e de uma branca de segunda, é o primeiro descendente legitimamente angolano. Quando nasce, a escrava que ajudava Esmeralda no parto o deixa cair na terra. Ao cair, a boca do menino toca o solo, mordendo-beijando o solo africano. Em seguida, é socorrido dessa queda pela mesma escrava: "A velha só chorava, lavandome" (PEPETELA, id. ibid., p. 9).

O toque do corpo da criança no solo africano é extremamente significativo para a narrativa. Quando a escrava deixa a criança cair no pó do solo angolano, Alexandre recebe seu primeiro batismo. Um batismo profano, sem deuses e sem ritos, acompanhado pelos olhares curiosos das gazelas. Já segundo batismo de Alexandre é dado pela escrava que o deixou cair ao chão. Lavando-o do pó, e acompanhando tal ritual com suas próprias lágrimas, a escrava estabelece uma forte ligação simbólica entre Alexandre e o solo africano, assim como ao próprio povo de Angola (ainda que tal ligação somente seja compreendida por Alexandre no momento em que seu neto Joel se engaja no combate armado pela independência da nação angolana). Esse "duplo batismo" funciona como uma espécie de rito de passagem, um marco que assinala as inúmeras contradições nas quais Alexandre cairá ao pensar sobre as revoltas dos negros, as segregações raciais e as diferenças internas que marcaram Angola sob o domínio colonialista (e que irão perdurar mesmo após a independência das ex-colônias africanas).

Assim, é possível averiguar que a "burguesia nacionalista" (termo que Said toma de empréstimo a Frantz Fanon) muitas vezes toma as rédeas da nação após movimentos de libertação e independência nacional reproduzindo as mesmas estratégias de dominação da metrópole colonialista:

\begin{abstract}
A idéia de uma independência total era uma ficção nacionalista voltada sobretudo para a "burguesia nacionalista" [...] a qual, por sua vez, com freqüência governava os novos países por meio de uma tirania espoliadora e empedernida que fazia lembrar os senhores que haviam partido (SAID, 1995, p. 51)
\end{abstract}

No caso específico de Angola, tal burguesia nacionalista tem suas raízes diretamente cravadas no passado dos colonos degredados. A estátua yaka é um elemento fundamental no texto de Pepetela. Tal como Alexandre, ela está presente

\footnotetext{
${ }^{1}$ Branco de segunda: termo pejorativo utilizado, à época colonial, para designar os brancos que nasciam em território africano. Tais colonos, nascidos na Colônia, eram considerados menos "portugueses" que os brancos degredados, nascidos em Portugal.
} 
desde o começo até o final da narrativa. Mas, ao contrário de Alexandre, cuja voz e visão conduzem a narração das histórias da dinastia Semedo, a estátua yaka funciona como um contraponto, algumas poucas vezes falando por si própria e emitindo juízos, é verdade, mas a maior parte do tempo funcionando como um mudo interlocutor de Alexandre, instigando-o com seus olhos de berlinde ${ }^{2}$ :

\begin{abstract}
- O meu pai ganhou essa estátua yaka no jogo. Já a tinha em Capangombe, quando casou. A minha mãe sempre a achou horrível com esses olhos de berlinde e estas três listras paralelas, branca, preta e vermelha. Repara, tem quase um metro de altura e corpo de homem, mas a cara é estranha, por vezes com aspecto humano, por vezes animal. [...] Parecia que tudo via. Impressão da minha mãe, claro. Mas herdei dela essa impressão. Sempre ficou na sala, em equilíbrio instável, pois o soco de madeira não é muito liso por baixo. Foi feita para estar no chão de terra batida, como esse por baixo das mangueiras dos quintais, chão liso por tanto ser varrido e pisado, mas aderente por causa da umidade. Porém, nunca caiu. [...] Sinto cada vez mais que ela me fala. Mas não entendo (PEPETELA, 1984, p. 22)
\end{abstract}

Alexandre Semedo continuará a não entender a fala-olhar da estátua yaka. É apenas no final da narrativa, após quatro gerações da dinastia Semedo, que aparecerá um descendente capaz de decifrar o olhar misterioso da estátua. Embora tanto Alexandre quanto sua mãe, Esmeralda, já tivessem percebido um brilho a querer falar nos olhos da estátua, é apenas Joel, neto de Alexandre, que irá desvendar o olhar da mesma. Auxiliado pelos comentários de Joel, Alexandre finalmente, pouco antes da morte, consegue dialogar com a estátua yaka. Isso ocorre por ocasião da investida dos sul-africães, que tomam Benguela por cem dias: "E só vai durar cem dias, cem obscuros dias, é certo, a ocupação de Benguela, porque os invasores vão recuar, empurrados pela frente e minados atrás pela guerrilha" (PEPETELA, 1984, p. 300).

Quem profere tal enunciado é a própria estátua yaka, que pela primeira e última vez se faz compreensível a Alexandre. Entretanto, ele só conhecerá a vitória de Angola através dos olhos de yaka, pois é sugerida, ao final da narrativa, a destruição do sapalalo $^{3}$, já corroído pelo salalé ${ }^{4}$, pelas explosões dos obuses sul-africães, disparados contra Benguela em uma tentativa de solapar as esperanças das Forças Armadas Populares de Libertação de Angola (FAPLA).

\title{
ANGOLANOS E ANGOLANAS, BRANCOS E NEGROS: DIFERENTES RAÇAS E DIFERENTES GÊNEROS SOB A ÉGIDE DE UMA MESMA NAÇÃO
}

Ao contrário do projeto romântico do século XIX (tanto no Brasil quanto na própria Europa) que pretende erguer, a partir da narrativa literárias, as bases para a construção de uma identidade nacional una e coesa, valorizando na construção narrativa elementos como a volta às origens (o período medieval, no romantismo europeu, ou a cor local e os povos autóctones, no caso do romantismo brasileiro), o romance póscolonial vai justamente problematizar essa idéia una, íntegra e monolítica que é a de identidade nacional. Tal como afirma Laura Cavalcante Padilha, em seu artigo intitulado "A diferença interroga o cânone",

\footnotetext{
${ }^{2}$ Berlinde: bola de gude.

${ }^{3}$ Sapalalo: construção residencial de dois andares, em madeira, semelhante a um sobrado.

${ }^{4}$ Salalé: o mesmo que cupim.
} 
Recortando o caso particular das Literaturas Africanas de Língua Portuguesa de forma geral e, de modo muito particular, o da angolana, objeto de nossa pesquisa, vemos começar a se impor a construção do cânone nas três últimas décadas deste século. Acontece com tais literaturas o ocorrido com a brasileira no século XIX, quando aquela construção se vincula a fundação literária da nacionalidade, num "regresso" à origem, no sentido de demarcar um centro. (PADILHA, 1997, p. 61)

Pepetela propõe-se a lançar bases para (re)criar mitos, de forma a solidificar uma identidade nacional angolana, mas seu projeto não pode ser reduzido simplesmente à criação de um capital simbólico, através do objeto literário, que represente uma identidade angolana. O autor de Yaka vai mais além, pois não apenas se engaja no processo de construção de uma identidade nacional, mas também problematiza essa identidade. Enquanto em Mayombe o autor privilegia a questão do tribalismo como um desses impasses que gera fronteiras internas à nação, e em Lueji: o nascimento dum império (1990) discute questões como a manutenção e ruptura com a tradição cultural, no romance $Y a k a$ são as questões de raça e de gênero que ganham o papel central.

Para iniciar essa discussão a respeito das questões de raça e de gênero dentro do período colonial, cabe mencionar uma passagem do romance. Alexandre, entrando na adolescência, forma um grupo de amigos com os quais passa as tardes brincando. Todos são brancos, à exceção de Tuca, único garoto negro admitido no grupo. Alexandre, a contar para a estátua yaka suas lembranças de infância, lembra-se de Tuca. Lembra-se também de que Tuca foi aceito no grupo de meninos brancos, ainda que negro, quando em suas brincadeiras "brincavam à guerra do Bailundo e o Tuca fazia de Mutu-yaKevela” (PEPETELA, 1984, p. 46). Mutu-ya-Kevela, que acabou por virar Quebera no falar dos colonos, foi o líder negro de uma das muitas revoltas do período colonial. Assim, por dar mais realismo à brincadeira dos meninos, fazendo o papel de Quebera, Tuca acabou aceito no grupo, tornando-se amigo próximo de Alexandre e, dadas as devidas proporções, também dos outros garotos brancos. A diferença racial (tal como a diferença de gênero) emergem na superfície textual por ocasião de uma outra lembrança de Alexandre: a do primeiro gozo, fruto do primeiro estupro:

Como daquela vez que estavam no Cavaco e passou uma rapariga negra dos seus treze anos. Eles estavam escondidos nas árvores, a se contarem estórias indecentes. Já excitados pela imaginação de Arnaldo, todos olharam para ela e viram era diferente.

- Vamos fazer de capitão Calado a tomar a aldeia de Samacaca - propôs o Amílcar.

- Vamos - disse Afonso - Vamos vingar as mulheres brancas.

O grupo correu para a rapariga, não deu tempo de fugir. Lhe agarraram e deitaram no chão. Ela gritou. Trazia só um pano enrolado à cinta que lhe puxaram com violência. $\mathrm{O}$ corpo jovem e nu, de menina, tomou cintilações acobreadas ao sol das quatro da tarde. Afonso foi o primeiro a cair em cima dela. A rapariga lutava e gritava, gritava e lutava. Alexandre pegou numa perna, Arnaldo na outra, separaram. Afonso já podia fazer o que queria. Fez. Depois foi o outro. E outro. Assim. A rapariga já não lutava, nem gritava. Os olhos estavam abertos, olhando os ramos das árvores que zumbiam com o vento. Tuca viu o que ela olhou, não viu o que ela via. Tuca não participou (id., ibid., p. 47) 
Tuca, ainda que aceito pelos meninos brancos, não perde em nenhum momento a consciência de que é negro. Se para os meninos brancos o ato de violentar uma menina negra é apenas uma diversão de final de tarde que não demanda maiores preocupações, para Tuca tal ato tem sentido completamente diverso. No momento em que Tuca cruza seus olhos com os olhos da menina, "viu o que ela olhou, não viu o que ela via". O que a menina olhou foram "os ramos das árvores que zumbiam no vento". Em contrapartida, o que ela viu foi a opressão promovida pelos homens brancos, tanto enquanto promotores do colonialismo quanto enquanto promotores das ideologias patriarcais e racistas. Tuca também olhou para os ramos das árvores, mas o que viu foi muito diferente: viu sua própria diferença, pois ao ler o ato de violação de uma garota negra do locus enunciativo de um sujeito negro, e não de um sujeito branco, notou que, mesmo sendo angolano como os outros garotos, algo o tornava dissonante frente ao grupo de amigos brancos. Logo, tornam-se evidentes os motivos que levam Tuca a não participar da "brincadeira" na qual os garotos se propõem a "vingar as mulheres brancas":

\footnotetext{
O bando deixou a menina no chão, os olhos abertos a olhar os ramos das árvores. Foram se esconder mais no fundo do Cavaco para comentarem. Depois de muito falarem da experiência, todos orgulhosos de serem machos de verdade, lembraram do Tuca.

- Por que não quiseste? - lhe perguntou Alexandre Semedo.

- É verdade, o Tuca não fez nada - disse Afonso.

- Por quê? - insistiu Alexandre. - Por ela também ser negra?

Tuca estava atrapalhado, torcia as mãos (PEPETELA, 1984, p. 47)
}

Alexandre percebe que, de alguma maneira, a filiação identitária de raça de Tuca pode ter impedido o garoto de participar da "brincadeira". Como se pode ver mais adiante, a percepção de Alexandre Semedo não vai além daquilo que poderia ser chamado de uma desleitura da diferença racial. Não se apercebendo que a oposição entre as raças branca e negra não está simplesmente localizada em uma dimensão horizontal, mas sim vertical (pois o negro está hierarquicamente subordinado ao branco), a inversão que Alexandre promove não consegue dar conta da lógica do racismo. Porém, as diferenças começam a tomar lugar nas falas dos garotos; talvez Tuca se "apetecesse", caso a garota fosse branca, e não negra, como se percebe na continuação do diálogo:

- Não foi por isso. Mas é porque ela não queria. Não gostou. Eu vi.

- Gostou, sim - disse Arnaldo. - Gozou que nem uma negra.

- Não gostou, eu vi - disse Tuca.

- E que interessa se ela gostou ou não? - disse Alexandre. - O que interessa é nós gozarmos. Ela não conta.

- Foi por isso que não me apeteceu.

- Se fosse uma branca, tu querias? - perguntou Arnaldo ao Tuca (id., ibid., p. 47-48)

Arnaldo, que possui também uma visão limitada dos conflitos do mundo colonialista, pensa poder reduzir a questão a uma simples oposição binária, na qual o termo raça, se invertido, justifica a manutenção da ordem falocêntrica, legitimando o abuso de mulheres, desde que essas sejam da raça outra, e não da própria. Entretanto, essa redução começa a ser desconstruída a partir do momento em que Amílcar mostra que não se pode simplesmente inverter os termos para tornar compreensível a atitude de Tuca. Assim, Tuca necessita de um suplemento, de um elemento que está "do lado de 
lá", exterior ao seu próprio discurso (comprometido com a dominação colonialista branca em Angola), para poder continuar a asseverar como legítimo o direito dos homens brancos de violar as mulheres negras. E tal suplemento será encontrado no discurso religioso, a partir do momento em que Amílcar recupera um enunciado produzido dentro do campo discursivo da religião, para tornar coerente sua opinião. Logo, ainda que se esteja falando de mulheres, a questão de raça mostra que, para os homens brancos, dois pesos e duas medidas são utilizadas quando se fala de mulheres:

- Xê, cala-te - disse Amílcar. - Isso é pecado.

- Também não queria - disse Tuca.

Os outros encolheram os ombros.

- Ó Amílcar, por que pecado? - perguntou Arnaldo.

- Então fazer isso com uma branca não é pecado?

Os outros concordaram, movendo as cabeças. Depois Afonso deu um empurrão no Tuca. Disse com desprezo:

- Este gajo não dá nada. Vamos lá compreender os negros! Arranjamos a melhor coisa para fazer e ele fica só a ver. Depois não digas que fomos nós que não deixamos (PEPETELA, 1984, p. 48)

\section{CONSIDERAÇÕES FINAIS}

A literatura angolana parece estar paramentada com todos os pré-requisitos necessários (e alguns extras, cabe lembrar) para que se construa - ufanisticamente - um cânone literário a partir de pressupostos nacionalistas que solapam as diferenças internas da nação. Padilha (1997, p. 61-64), em seu trabalho com as Literaturas Africanas de Língua Portuguesa, ao interrogar o cânone a partir de levantamento feito em várias antologias de escritores africanos, chega à conclusão que muitas das estratégias discursivas utilizadas pela crítica dessas literaturas provenientes de excolônias reproduzem padrões muito semelhantes aos do discurso colonialista. Entre eles, o de exclusão das obras de autoria feminina, visto que lugar da mulher é o domínio do privado $^{5}$, o lar e a família, e não o domínio da esfera pública, lutando pelo direito à representação, seja pelo direito à autoria, como produtora de bens simbólicos (representações culturais), seja pelo direito à entrada no universo político, no qual as mulheres - via de regra - não possuem representatividade.

Ainda na questão do apagamento das diferenças internas, Padilha lembra de uma outra questão extremamente importante ao se tratar da literatura produzida nas excolônias: o fato de que a crítica - grande responsável pela interpretação e canonização das obras literárias - relativa a literatura das ex-colônias é produzida fora dos territórios onde essas literaturas são produzidas:

Lembrando o fato de o acervo crítico dessas literaturas [a saber: Literaturas Africanas de Língua Portuguesa] se ter forjado inicialmente fora da África na Europa e nas Américas, com Portugal e Brasil à frente - começamos por questionar até que ponto o cânone, "consagrado" por outras vozes que não as africanas, submeteu-se aos mesmos mecanismos de dominação e poder que

\footnotetext{
${ }^{5}$ Quanto ao papel da mulher dentro da nação, conferir o artigo: SOMMER, Doris. "Amor e pátria na América Latina: uma especulação alegórica sobre sexualidade e patriotismo”. In: HOLLANDA, Heloísa Buarque de. Tendências e impasses: o feminismo como crítica da cultura. Rio de Janeiro: Rocco, 1994. p. 158-183. Conferir também PRATT, Mary Louise. "Mulher, literatura e irmandade nacional", incluído no mesmo volume que o artigo anterior, p. 127-157.
} 
sempre tiveram como meta elidir as diferenças, sobretudo se o objetivo recortado são questões como as de gênero e raça (PADILHA, 1997, p. 62)

Se o nascimento de um cânone literário é pautado na "homogeneização" da identidade nacional, apagando as diferenças internas à comunidade nacional, é justo afirmar que a obra de Pepetela não compactua com a exaltação de um nacionalismo nesses termos configurado. Indo de encontro a esse tipo de reducionismo típico de momentos nos quais se faz necessária a construção de uma identidade nacional através de representações culturais (mais especificamente, a literatura), o universo diegético de Pepetela, ao invés de elidir as diferenças, as salienta, dificultando as possibilidades de dispor a literatura angolana a serviço daquela "burguesia nacionalista" da qual fala Said. Destarte, Pepetela contribui não somente com a construção de uma identidade nacional em Angola (entende-se aqui por "identidade" não uma categoria essencializada, mas sim processual e coletivamente erigida), mas também contribui, através de sua obra, para que as categorias de identidade nacional sejam revistas. Ao contrário de uma identidade una e coesa, o que o universo ficcional de Pepetela traz é uma Angola marcada pelas diferenças internas, cingida enquanto nação por um discurso que assume suas próprias contradições.

\section{REFERÊNCIAS}

BHABHA, Homi K. O local da cultura. Belo Horizonte: UFMG, 1998.

HUTCHEON, Linda. A Poetics of Postmodernity: history, theory, fiction. Nova York: Londres: Routledge, 1988.

PADILHA, Laura Cavalcante. A diferença interroga o cânone. In: SCHMIDT, Rita Terezinha (org.) Mulheres e literatura: (trans)formando identidades. Porto Alegre: Palloti, 1997. p. 61-69.

PEPETELA. Mayombe. São Paulo: Ática, 1982.

PEPETELA. Lueji: o nascimento dum império. Lisboa: Dom Quixote, 1990.

PEPETELA. Yaka. São Paulo: Ática, 1984.

PRATT, Mary Louise. Mulher, literatura e irmandade nacional. In: HOLLANDA, Heloísa Buarque de. Tendencias e impasses: o feminismo como crítica da cultura. Rio de Janeiro: Rocco, 1994. p. 127-157.

SAID, E. Cultura e imperialismo. São Paulo: Companhia. das Letras, 1995.

SOMMER, Doris. Amor e pátria na Améria Latina: uma especulação alegórica sobre sexualidade e patriotismo. In: HOLLANDA, Heloísa Buarque de. Tendências e impasses: o feminismo como crítica da cultura. Rio de Janeiro: Rocco, 1994. p. 158183. 